\title{
Interspecific variation in plumage colour among birds: species recognition or light environment?
}

\author{
MELINDA K. MCNAUGHT*† \& IAN P. F. OWENS $\$$ \\ *Department of Zoology and Entomology, University of Queensland, St Lucia, Brisbane, Queensland, Australia \\ $\dagger$ Department of Primary Industry Fire Ant Control Centre, PO Box 1241, Oxley, Queensland, Australia \\ $\$$ Department of Biological Sciences and NERC Centre for Population Biology, Imperial College at Silwood Park, Ascot, Berkshire, UK
}

\section{Keywords:}

birds;

colour;

light environment;

plumage;

signalling;

species recognition.

\begin{abstract}
The traditional explanation for interspecific plumage colour variation in birds is that colour differences between species are adaptations to minimize the risk of hybridization. Under this explanation, colour differences between closely related species of birds represent reproductive character displacement. An alternative explanation is that interspecific variation in plumage colour is an adaptive response to variation in light environments across habitats. Under this explanation, differences in colour between closely related species are a product of selection on signal efficiency. We use a comparative approach to examine these two hypotheses, testing the effects of sympatry and habitat use, respectively, on divergence in male plumage colour. Contrary to the prediction of the Species Isolation Hypothesis, we find no evidence that sympatric pairs of species are consistently more divergent in coloration than are allopatric pairs of species. However, in agreement with the Light Environment Hypothesis, we find significant associations between plumage coloration and habitat use. All of these results remain qualitatively unchanged irrespective of the statistical methodology used to compare reflectance spectra, the body regions used in the analyses, or the exclusion of areas of plumage not used in sexual displays. Our results suggest that, in general, interspecific variation in plumage colour among birds is more strongly influenced by the signalling environment than by the risk of hybridization.
\end{abstract}

\section{Introduction}

Why do different species of birds have different coloured plumage? The adaptive significance of interspecific variation in avian coloration has been the subject of a longrunning debate and many explanations have been put forward (see Darwin, 1871; Wallace, 1889; Huxley, 1942; Mayr, 1942, 1963; Lack, 1968, 1976; Baker \& Parker, 1979; Hamilton \& Zuk, 1982; Endler, 1993; Marchetti, 1993; Andersson, 1994; Savalli, 1995; Endler \& Thery, 1996; Zahavi \& Zahavi, 1997; Price, 1998; Andersson 2000). There have been, however, very few attempts to use modern comparative methods to estimate the relative

Correspondence: Ian P. F. Owens, Department of Biological Sciences, Imperial College at Silwood Park, Ascot, Berkshire SL5 7PY, UK. Tel.: +44 207594 359; fax: +44 207594 2339, e-mail: i.owens@ic.ac.uk importance of these competing explanations (Owens $\delta$ Clegg, 1999; Bennett \& Owens 2002).

The traditional explanation for interspecific plumage colour variation is that such colour differences serve to minimize the risk of hybridization (see Wallace, 1889; Dobzhansky, 1940; Huxley, 1942; Mayr, 1942, 1963; Grant, 1965, 1975; Lack, 1968, 1971). This 'Species Isolation Hypothesis' has typically been supported by reference to apparent cases of reproductive character displacement between sister taxa in areas of sympatry, often illustrated by comparisons between red-winged (Agelaius phoeniceus) and tricoloured blackbirds (A. tricolor) in North America, or pied (Ficedula hypoleuca) and collared flycatchers (Ficedula albicollis) in Northern Europe (Hardy \& Dickerman, 1965; Alatalo et al., 1994; Saetre et al., 1997). However, despite the frequency with which the Species Isolation Hypothesis has been invoked 
to explain interspecific variation in plumage colour, there have been very few large-scale comparative tests. It is unknown therefore whether the Agelaius blackbirds and Ficedula flycatchers illustrate a general pattern, or whether such reproductive character displacement in plumage characters is idiosyncratic to a small proportion of bird species.

A second explanation for interspecific variation in plumage colour is that different species use different colours because they inhabit different light environments (e.g. Endler, 1993; Marchetti, 1993; Endler \& Thery, 1996; Zahavi \& Zahavi, 1997; Andersson 2000). Several authors have made explicit predictions concerning which colours are most suitable for use in which light environments, based on maximizing contrast against the background in the dominant ambient light environment (see Endler, 1993; Marchetti, 1993; Endler \& Thery, 1996; Zahavi \& Zahavi, 1997; Andersson 2000). For instance, in relatively 'Closed' habitats, such as forests and woodland, oranges and reds are predicted to be used in signalling because these colours reflect the long wavelength light that dominates the ambient light spectrum in these habitats and contrast well against the surrounding vegetation (Endler, 1993). Additionally, species that live in relatively Closed habitats should have generally more reflective, or 'brighter', plumage than those species living in relatively 'Open' habitats, because the overall level of luminescence is lower in relatively closed habitats (Marchetti, 1993). Once again, however, although one or two supportive examples have been found for each of these predictions (see Mayr \& Stresemann, 1950; Orians \& Christman, 1968; Bretagnolle, 1993; Zahavi \& Zahavi, 1997) there have been rather few statistically robust comparative tests (but see Marchetti, 1993; Endler \& Thery, 1996). It remains to be discovered, therefore, whether the Light Environment Hypothesis can account for general patterns in plumage colour evolution in birds.

The overall aim of this study is to combine objective methods of colour measurement with statistically rigorous comparative analyses to investigate the relative ability of the Species Isolation Hypothesis and the Light Environment Hypothesis to explain interspecific variation in plumage colour among birds. We test two predictions. The first prediction is that, if avoidance of harmful hybridization is the dominant force influencing plumage colour variation in birds, then there should be more pronounced divergence in plumage colour between sympatric pairs of species than between allopatric pairs of species (Fisher, 1930; Mayr, 1963; Lack, 1968, 1971). This is the classic 'reproductive character displacement' test (see Huxley, 1942; Mayr, 1942, 1963; Grant, 1965, 1975; but see Paterson, 1978, 1982, 1985, 1993). The second prediction is that, if differences between species in colour use are due primarily to differences in light environment, then interspecific variation in plumage colour should be associated with interspecific variation in habitat use. We test each of these predictions using matched-pairs analyses across a subsample of Australasian bird groups.

\section{Methods}

In order to carry out a large-scale comparative analysis of plumage colour in birds, methods are needed to, first, obtain a quantitative description of 'colour', second, make statistical comparisons between different colours, and third, collect colour information from a large number of species with divergent patterns of geographical distribution and habitat use.

To satisfy the first of these criteria, we used reflectance spectrometry to obtain a quantitative description of plumage colours. Compared with subjectively scoring plumage colours as 'dull' vs. 'bright', or 'red' vs. 'brown', this method has the advantage of not being dependent either on the human visual system nor on preconceived notions of colour variation (Cuthill et al., 1999). We collected reflectance spectra using an Ocean Optics S2000 spectrometer and an Ocean Optics DH2000 TungstenDeuterium light source following established protocols (see Endler, 1990, 1993; Finger \& Burkhardt, 1994; Endler \& Thery, 1996; Hausmann, 1997; Arnold et al., 2002; Hausmann et al., 2002). All reflectance spectra were relative to a white 'Spectralon' tablet. The geometry of sampling was normal to the surface of the plumage area being examined and with illumination held at $45^{\circ}$. Each reading was an average of three measurements from the same area of plumage, with five individuals being measured from each species. All individuals were adult males.

To satisfy the second criterion, the main method that we employed to make comparisons between reflectance spectra was Endler's (1990) 'segment analysis'. The advantages of this method for the particular analyses that we performed were threefold. First, it allowed us to calculate differences in 'hue' and 'brightness' per se, which are the colour parameters upon which light environment predictions are currently based. Secondly, it allowed us to calculate the 'total distance' between different colours, which is useful when testing for character displacement. Thirdly, because the values that segment analysis ascribed to colours were absolute, it was straightforward to make comparisons across different databases. Segment analysis does, of course, also have disadvantages. The most severe of these was that it was not explicitly based on the visual system of the likely receivers. This made it difficult to interpret differences in colour in terms of differences in perception. Such extrapolation would have been better facilitated using a model that is explicitly based on the visual system of birds, such as that recently developed by Vorobyev et al. (1998), although even Vorobyev et al.'s (1998) is restricted to analysing the four types of single cone typically found on the avian retina, thereby ignoring the double cones that are thought to 
play an important role in the perception of overall luminosity (Osorio et al., 2001). Additionally, because the values that segment analysis ascribed to colours were absolute, it may not have extracted as much statistical power from a database as would have a method such as principle component analysis (Grill \& Rush, 2000). Nonsignificant results should therefore be treated with particular caution. Despite these shortcomings we used segment analysis because, for these particular analyses, we considered that the advantages outweighed the disadvantages, particularly in regard to being able to make precise tests of predicted changes in 'hue' and 'brightness'. Nevertheless, in order to ensure that our results were not artefacts of the methods we employed, all of the analyses presented in this study were also repeated using spectra measurements based on direct analysis of spectral shape. We used direct measurements of spectral shape as the alternative method of analysis because it (1) provides indices that are easily comparable to notions of 'hue' and 'brightness', (2) makes no assumptions concerning the way in which optical signals are processed, (3) gives an independent series of tests from Endler's segment analysis, and (4) is simple to describe. In all cases the results obtained using these other methods were qualitatively identical to those obtained using Endler's segment method.

To satisfy the third criterion, we used to museum specimens for colour measurement. The great advantage of using museum skins was that a large number of species could be studied within a relatively short period of time. The potential disadvantage, of course, is the possibility of fading due to the age of the specimens, and/or the preservation method employed. In order to address this potential problem, both Endler \& Thery (1996) and Hausmann (1997) examined the occurrence of fading in museum specimens, and both groups found that fading between museum specimens was not sufficient to cause misinterpretation. In older specimens, the greatest loss of colour occurred in terms of brightness, but hue appeared to be largely unaffected even in very old skins (>150 years; Hausmann, 1997). The use of museum specimens for the examination of colour is, therefore, appropriate (see Endler \& Thery, 1996; Hausmann et al., 2002). For the purposes of this study bird 'skins' preserved at the Queensland Museum (Brisbane, Australia) were used for data collection, using only those specimens that were collected after the 1950s, with the majority having been collected between 1970 and 1980. Species were chosen from the parrots (Psittacidae), honeyeaters (Meliphagidae), estrildid finches (Estrildidae), fairy wrens (Maluridae), Papua-Australian robins (Petroicidae) and whistlers (Pachycephalinae) for use in a series of matched-pair analyses. These taxonomic groups were chosen because they have several species resident to the Australian mainland, were represented by a large number of museum specimens, and are classic examples of biogeographical variation in Australian fauna. In particular, for each of these families there is a well-established pattern of sympatry and allopatry with respect to putative Pleistocene refugia (Cracraft, 1986; Ford, 1987). Overall, in excess of 4500 reflectance spectra were measured on more than 325 individual museum specimens, representing 65 species.

\section{Test 1: Light environment hypothesis}

The Light Environment Hypothesis predicts that differences in colour between species will be associated with consistent differences in habitat because different habitats tend to be associated with different light environments. Here, we tested two Light Environment Hypothesis predictions: that species living in relatively Closed environments should tend to make more use of long wavelength colours, such as red and orange, than do those living in relatively Open environments (Endler, 1993); and that species in relatively Closed environments should have plumage that reflects more light than those living in relatively Open environments (Marchetti, 1993). Thus, in terms of Endler's (1990) segment analysis method, the Light Environment Hypothesis makes the quantitative prediction that the adoption of relatively Closed habitats should be associated with colours of high 'hue' value and high 'brightness' value. Hue and brightness were calculated using the methods described by Endler (1990), corresponding to $H$ and $Q$ under his notation.

All tests were also repeated using direct measurements of spectral shape. The alternative estimate of 'hue' was the wavelength at which the percentage reflection was greatest. The alternative estimate of 'brightness' was the entire photon catch across visible wavelengths. Henceforth, these two measures will be referred to as 'maximum wavelength' and 'total luminosity', respectively.

To test the predicted relationships between colour and light environment, we collated reflectance spectra from the plumages of 20 matched-pairs of species. Each pair comprised a pair of closely related species, one of which lives in a relatively Open habitat and the other of which lives in a relatively Closed habitat (see Appendix 1). Habitats were classified as follows: relatively Open habitats included deserts, arid regions, grasslands, heathland, wooded grasslands, open woodland; relatively Closed habitats included closed woodland, mangroves, reed beds and rank grass, monsoonal forest, open forest, tall wet forest, rainforest. Details of habitat use by each species were obtained from Strahan (1991), Serventy (1982) and Simpson (1984). Species that were reported as using both relatively Open and relatively Closed habitats in approximately equal proportion were not included in the matched-pairs. Where a species was recorded as having geographical races defined on the basis of colour, we ensured that we used a race that showed the appropriate pattern of habitat use. 
We recognize that 'Open' and 'Closed' are very crude indices of light environment, not only because they refer to relative difference between habitats, but also because there can be great variation within a habitat in terms of light environment. For example, although rainforests are usually thought of as relatively Closed habitats, species inhabiting the upper canopy of rainforests may experience a light environment more similar to that usually associated with relatively Open habitats. Ideally therefore we would restrict our analyses to those species that are known to actually display in light environments typical of relatively Open and Closed habitats, respectively. Unfortunately, because the exact display position of many Australasian species is not recorded in handbooks, such analyses much await future investigation. In the meantime, therefore, it is important to keep in mind that tests based on crude indices of light environment must be biologically very conservative and nonsignificant results must be treated with great caution.

We collected reflectance spectra from all plumage colours from all regions of the body. For each colour we calculated the mean reflectance spectra from three repeated measures on each specimen and the repeated measures across five different male specimens. We then used Endler's method of segment analysis to calculate value for brightness and hue for each plumage colour, and direct spectral analysis to estimate maximum wavelength and total luminosity. We then identified which plumage colours occurred in which body regions and calculated an average value of brightness, hue, maximum wavelength and total luminosity for each body region. We used five body regions: (i) head, throat and nape; (ii) chest, flanks belly and vent; (iii) back and rump; (iv) wings and (v) tail (see Owens $\delta$ Bennett, 1994; Owens \& Hartley, 1998; Owens \& Clegg, 1999; Hausmann et al., 2002). We then calculated a mean value for brightness, hue, maximum wavelength and total luminosity across all five body regions, which we subsequently refer to as mean total values. Because hue is an angular vector we used circular statistical procedures to calculate mean values (Zar, 1974).

Finally, we tested whether there were consistent differences between relatively Closed and relatively Open dwelling species in terms of brightness, hue, maximum wavelength and total luminosity. Initially, we preformed these tests simply on the mean total values, but subsequently we reanalysed the data using values only from those body regions recorded as being erected, shaken or otherwise moved in active courtship displays (see Hausmann et al., 2002). Data concerning which body regions are so used in active displays for each species was obtained from Schodde \& Tidemann (1997), Strahan (1991, 1992, 1996), Serventy (1982), Immelmann (1965) and Forshaw (1989). For brightness, maximum wavelength and total luminosity we used the Wilcoxon Ranked Sum Pairs test to test for consistent patterns across matched-pairs. Because hue is an angular vector, however, we used a paired version of Moore's (1980) test, which is the circular statistics equivalent of the Wilcoxon test (Zar, 1974). All tests were two-tailed and performed using JMP 4.1 (SAS Institute, 2001) except the Moore's tests, which were performed by hand.

\section{Test 2: Species Isolation Hypothesis}

The Species Isolation Hypothesis predicts that, if avoidance of hybridization is a major selective force in the evolution of plumage colour, colour divergence should be greater between pairs of species living in sympatry than between pairs of species living in allopatry. To test this prediction we identified 20 sets of trios, each trio comprising two sets of matched-pairs of closely related species. In each trio, therefore, there was a pair of species that live in sympatry and a pair of species that live in allopatry, with one species being in common to both pairs (see Appendix 2). 'Sympatric' and 'Allopatric' pairs of species were chosen using the distribution maps found in Pizzey's (1980) and Simpson's (1984) field guides, with the definition for Sympatric pairs of species being that their breeding ranges overlapped by an area equivalent to at least $25 \%$ of the entire breeding range of one of the species. In most cases the breeding ranges of Sympatric pairs overlapped by a proportion much greater than this. The definition for Allopatric pairs of species was that their breeding ranges did not overlap at all. In the case of Sympatric pairs, care was taken to ensure that the two species represented each others' closest extant phylogenetic relative with a Sympatric distribution. Thus, even if there was no direct evidence of ongoing hybridization, then they should still represent the most likely risk of hybridization. Where a species was recorded as having geographical races defined on the basis of colour, we ensured that we used a race that showed the appropriate pattern of sympatry or allopatry, as required.

Again, we measured the reflectance spectra for all plumage colours across all body regions and then, for each body region for each pair of species, we identified the pair of colours that are most different in terms of Endler's (1990) method of calculating total Euclidean distance between spectra. Having identified the most divergent spectra for each body region for each pair of species, we then calculated for each pair of species the mean divergence between spectra across all body regions. We refer to this as the mean total divergence between a pair of species. All analyses were repeated using direct measurement of spectral shape, with overall spectral overlap (Endler, 1990) being the alternative index of divergence between colours.

We then used a paired Wilcoxon ranked sum analysis to test whether, across all trios, the mean total divergence (or overall spectral overlap) between species tended to be consistently greater for sympatric matched-pairs than it was for matching allopatric pairs. Initially, this test was performed using spectral data from all body regions, and 
subsequently we repeated the analysis using spectral data from only that body region that was shown to be the most divergent for the sympatric pair of species within any trio. This second test was carried out to maximize the chances of detecting character displacement if it did occur. All tests were two-tailed and performed using JMP 4.1 (SAS Institute, 2001).

\section{Results}

\section{Test 1: Light environment hypothesis}

Our analyses revealed that, as predicted by the light environment hypothesis, the use of relatively Closed habitats was associated with significant increases in values of mean total hue. In 14 of 20 matched-pairs, the species from the relatively Closed habitat had a higher mean total hue value than the species from the relatively Open habitat (Fig. la). This was also true when we restricted our analyses to only those body regions recorded as being used on courtship displays (Fig. 1b). All of these results remained unchanged when we based our tests on direct measures of spectral shape, with the species from the relatively Closed habitat having the longer maximum wavelength across all body regions in 13 of 18 species pairs $(z=2.48, n=18, P<0.01)$ and species from the Closed habitat having the longer wavelength in displayed regions in 8 of 10 species pairs $(z=2.31, n=10, P<0.05)$.

Our results did not, however, agree with the prediction that the use of relatively Closed habitats should be associated with more reflective plumage. Instead, we found that the adoption of relatively Closed habitats is associated with lower values of mean total brightness. In 16 of 20 matched-pairs the species from the relatively Open habitat had a higher mean total brightness value than the species from the relatively Closed habitat (Fig. 1c). Again, this was also true when we restricted our analyses to only those body regions recorded as being used on courtship displays (Fig. 1d), or used total luminosity as an index of brightness (all body regions; $z=2.39, n=20$, $P<0.05$ : display regions only; $z=2.15, n=20$, $P<0.05)$.
Fig. 1 Associations between habitat use and colour. Using analyses based on all body regions, associations between variation in habitat use (relatively Open vs. relatively Closed) and variation in (a) hue, and (b) brightness. Using analyses based only on those body regions recorded as being used in courtship displays, associations between differences in habitat use and (c) hue, and (d) brightness. In the analyses dealing with hue, statistics refer to paired Moore (1980) tests as described in Zar (1974). In the analyses dealing with brightness, the statistics refer to Wilcoxon Signed-Ranked Pairs tests. (a) Hue: all body regions

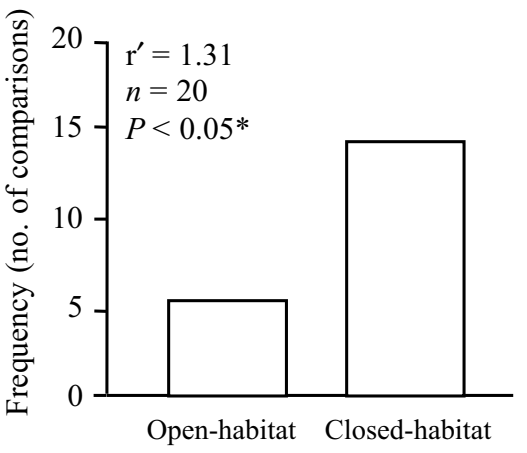

Species with highest hue value

(c) Brightness: all body regions

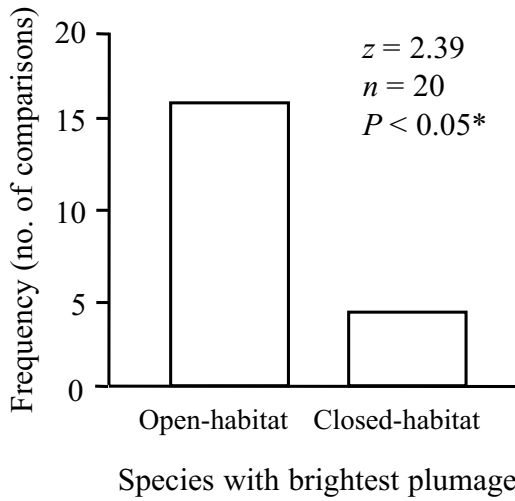

(b) Hue: diplay regions only

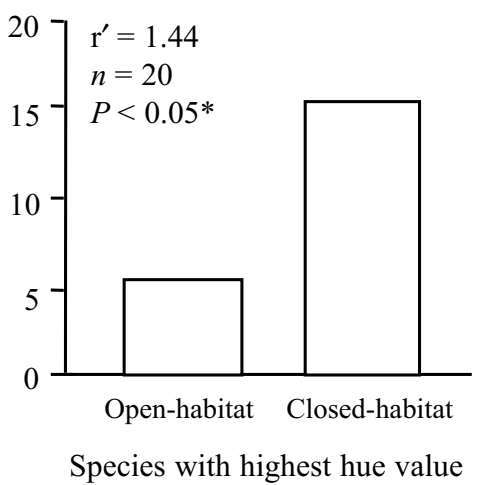

(d) Brightness: display regions only

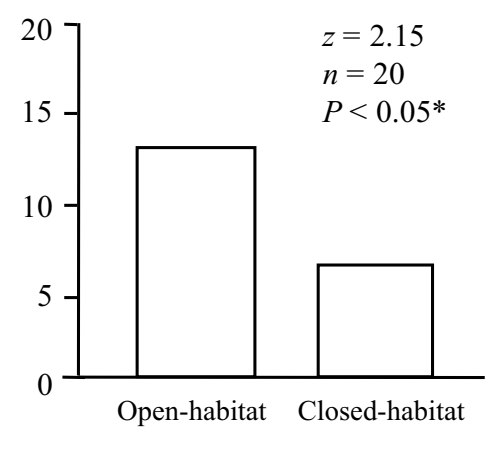

Species with brightest plumage 
(a) All body regions

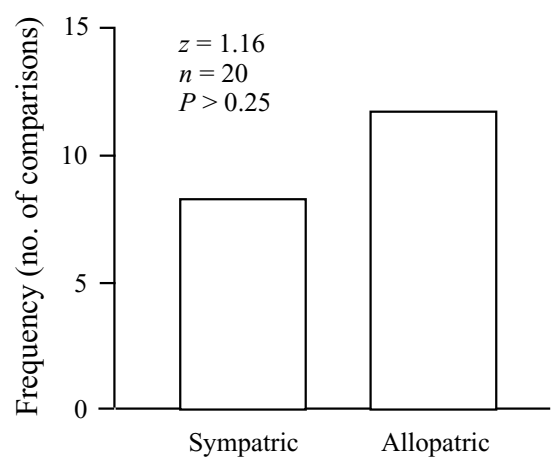

Most divergent pair of species (b) Regions of maximum contrast

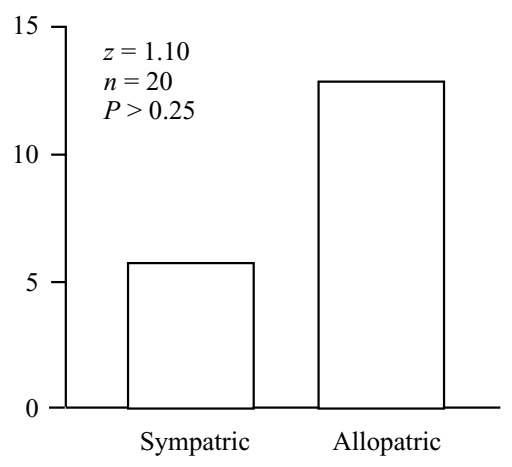

Most divergent pair of species
Fig. 2 Associations between patterns of sympatry and divergence in coloration (a) based on all body regions, and (b) based on only those body regions that show maximal divergence in colour. All statistics refer to Wilcoxon Signed-Ranked Pairs tests.

\section{Test 2: Species Isolation Hypothesis}

Our results did not conform to the predictions of the Species Isolation Hypothesis. There was no consistent difference between the sympatric and allopatric pairs of species with respect to the extent of divergence of colour patterns. Overall, the sympatric pair of species was more divergent than the allopatric pair in only 8 of 20 trios (Fig. 2a). Once again, this result remained the same when we restricted our analyses to only those body regions that showed the greatest divergence between the sympatric pair of species in each trio, in which case the sympatric pair of species was more divergent than the allopatric pair in only 6 of 20 trios (Fig. 2b). This was because the body region that was most divergent for the sympatric pair of species tended to be the same body region that was most divergent for the allopatric pair of species. It was also true when we based our analyses on direct measurement of spectral shape, with sympatric pairs being more divergent than allopatric pairs in only 7 of 20 trios when all body regions were considered together $(z=1.27, P>0.20)$, and in only 9 of 20 trios when only regions of maximum divergence were considered $(z=0.57, n=20, P>0.50)$.

\section{Discussion}

Our results provide strong support for the hypothesis that interspecific variation in plumage coloration is associated with interspecific variation in light environments. We found significant associations between patterns of habitat use and interspecific variation in values of both hue and brightness. In the case of the association between habitat use and hue the relationship was in the direction predicted by Endler (1993), with species from relatively Closed habitats using colours that were more likely to be rich in long wavelengths than were those colours used by species from relatively Open habitats. This finding therefore agrees with the notion that plumage colour is adapted to provide maximum chromatic contrast against backgrounds taking into account ambient light conditions (see Endler, 1993; Endler \& Thery, 1996), although comparative analyses alone cannot prove such a causal link (Bennett \& Owens, 2002).

In the case of the association between habitat use and brightness, on the other hand, the direction of the relationship was in the opposite direction to that found by Marchetti (1993), with species from relatively Closed habitats using colours that were less bright that those used by species from relatively Open habitats. Our finding therefore agrees more with Zahavi \& Zahavi's (1997) prediction that species in relatively Open habitats should be more likely to use highly reflective plumage because these spectra maximize contrast over long distances. This finding therefore supports the hypothesis that interspecific variation in plumage colour may be an adaptation to differences in the distance over which signalling may take place (Zahavi \& Zahavi, 1997), although again comparative analyses alone cannot prove this sort of causal link (Bennett \& Owens 2002). However, it should also be kept in mind that, as well as our tests being rather conservative because of the crude way in which we scored variation in light environments, there are also important methodological differences between our work and that of Marchetti (1993). Although we measured variation in the luminosity of the colours themselves, Marchetti (1993) measured variation in the size of bright patches of plumage. We did not account for patch size in our calculations. It seems likely, therefore, that the relationship between habitat use and plumage brightness may be rather complex, with the adoption of relatively Closed habitats perhaps leading to a general reduction in the brightness of the plumage (this study) but an increase in the size of a small number of highly reflective patches of plumage (Marchetti, 1993).

In contrast to our findings in support of the light environment hypothesis, our results did not confirm the 
key prediction of the Species Isolation Hypothesis. We found no consistent effect of sympatry on the extent of interspecific divergence in coloration between pairs of closely related bird species. In the majority of cases, the sympatric species were, in fact, more similar to one another than the allopatric species. This was the case even when the analysis was restricted to those areas of maximum contrast between sympatric pairs, as well as for those regions used in display. The same results were also obtained irrespective of which analytical methods were used to quantify variation in plumage coloration. The fact that the sympatric species were not unusually more different from one other than expected by chance, suggests that among the species that we examined the need for species recognition is not an important determinant of interspecific variation in plumage colour.

This lack of support for the species isolation hypothesis should be tempered by the fact that, although the sympatric pairs of species in our database are the closest extant sympatric relatives of each other, in most cases there is no known history of hybridization. This means that reinforcement is unlikely to occur and character displacement may be expected to be relatively weak. It remains plausible, therefore, that selection for species recognition may affect the evolution of plumage in those species that face a high risk of hybridization, such as the Agelaius blackbirds and Ficedula flycatchers. The question is, how common is such a process? Our results suggest that, although such cases have been widely used in discussions of speciation in birds, character displacement with respect to plumage coloration is rare. We suspect that, in Australian birds at least, most diversification occurs in allopatry (see Mayr, 1942, 1963; Lack, 1976; Barraclough \& Vogler 2000; Coyne \& Price 2000).

Another important caveat to our work on the species isolation hypothesis is that it is based on the view that the primary function of species-specific signals is to minimize the risk of harmful hybridization with closely related species. Indeed this is the origin of the prediction that sympatry should lead to reproductive character displacement. There is, however, a very different form of the species isolation hypothesis, which has been developed by Paterson (1978, 1982, 1985, 1993) and which he terms the 'specific-mate recognition hypothesis'. Under Paterson's hypothesis, the primary function of speciesspecific signals is to allow individuals to recognize members of their own species, rather than to avoid members of other species. Although the difference between the traditional species isolation hypothesis and Paterson's specific-mate recognition hypothesis may be subtle in terms of words, the difference is profound in terms of the tests presented here. Because Paterson's hypothesis does not predict reproductive character displacement in sympatry, it is not falsified by our finding that sympatric species appear to be not more divergent than allopatric species. Hence, as far as our results are concerned it remains plausible that, as Paterson has repeatedly suggested (for review see Paterson, 1993), interspecific variation in species-specific signals is due to interspecific variation in the most effective means of signalling to other members of the same species, which may in turn be due to interspecific variation in the signalling environment. Viewed in this way, the light environment hypothesis is closely allied to Paterson's specific-mate recognition hypothesis.

Such speculation must, however, be weighed by the limitations of our analyses, some of which are general to all comparative analyses and some of which are specific to our particular study. The most relevant general limitation is that comparative analyses cannot unambiguously determine the direction of causal functional relationships (Harvey \& Pagel, 1991; Bennett \& Owens 2002). Thus, there is no way of confidently concluding that a difference in light environment is primarily determining colour variation rather than vice versa. Equally, we cannot exclude the possibility of unmeasured variables confounding the relationship that we have identified (Bennett \& Owens, 2002). A large number of hypotheses have been put forward to explain interspecific variation in plumage colour (see Savalli, 1995) and we have only considered a handful of variables. Empirical experiments are required to test these functional hypotheses (Bennett \& Owens, 2002).

Turning now to the limitations of our particular study, in addition to those that we have already mentioned in this discussion we are aware of three additional substantial limitations: (1) the method of segment analysis is not based on the visual system of the receiver; (2) we have little knowledge of which plumage colours are used for signalling and which are used for crypsis; and (3) we have no detailed knowledge of the light environment in which, and the background against which, signalling actually takes place. In each case, we have, however, attempted to minimize the possible effect of these weaknesses. For instance, we repeated all of the tests carried out here using alternative methods of quantifying colour variation and all results remained qualitatively unchanged. Equally, all results remain qualitatively unchanged when we repeat analyses based only on those body regions either known to be involved in courtship behaviours or those body regions showing maximal divergence between the sympatric pairs species. Indeed, we even obtain qualitatively the same results if we analyse each body region separately, with the head region showing particularly strong associations with habitat use. Finally, we have specifically selected species that show clear differences in habitat use despite complications arising from patterns of migration and territorial defence. Thus, although more detailed work is undoubtedly required, we hope that these results are sufficiently robust to prove of some value in the ongoing search for an adaptive explanation for interspecific variation in plumage colour. 


\section{Conclusions}

We have performed a series of analyses on the coloration of 65 species of Australian birds, including representatives from six major groups. Our results suggest that, although the need to avoid hybridization may have a strong influence in the evolution of other traits, such as behavioural displays and song (Sung \& Park, 1994; Park et al., 1995; Naguib \& Todt, 1998), it does not appear to be the most important force behind the evolution of plumage colour in this group of birds. Although a few classic cases, such as the Agelaius blackbirds and Ficedula flycatchers, provide a convincing example of adaptations to facilitate species isolation, such cases of reproductive character displacement appear to be the exception rather than the rule. In general, sympatric species are not more divergent with respect to plumage colour. Interspecific plumage colour divergence appears to be more strongly influenced by the signalling conditions created by different patterns of habitat use, rather than the need to look different from other species. These findings are consistent with the hypotheses that variation in speciesspecific coloration is strongly influenced by differences in species-specific signalling conditions (Endler, 1993; Marchetti, 1993; Endler \& Thery, 1996; Zahavi \& Zahavi, 1997).

\section{Acknowledgments}

We thank the Queensland Museum for allowing us access to their collection; and Andrew Amey, Kate Arnold, Peter Bennett, Mark Blows, Ken Chan, John Endler, Franziska Hausmann, Jiro Kikkawa, Justin Marshall, Valérie Olson, Daniel Osorio, Devi StuartFox, Cas Vanderwoude and Misha Vorobyev for practical help, discussion and/or comments on previous drafts of the manuscript. This work was funded by the Australian Research Council and the University of Queensland.

\section{References}

Alatalo, R.V., Gustafsson, L. \& Lundberg, A. 1994. Male coloration and species recognition in sympatric flycatchers. Proc. R. Soc. Lond. Ser. B 256: 113-118.

Andersson, M. 1994. Sexual Selection. Princeton University Press, Princeton.

Andersson, S. 2000. Efficacy and content of avian colour signals. In: Animal Signals: Signalling and Signal Design an Animal Communication (Y. Epsmark, T. Amundsen \& G. Rosenqvist, eds), pp. 47-60. Tapir Academic, Trondheim.

Arnold, K.E., Owens, I.P.F. \& Marshall, N.J. 2002. Fluorescent signalling in parrots. Science 295: 92.

Baker, R.B. \& Parker, G.A. 1979. The evolution of bird plumage coloration. Philis. Trans. R. Soc. Lond. Ser. B 287: 63-130.

Barraclough, T.G. \& Vogler, A.P. 2000. Detecting the geographic pattern of speciation from species-level phylogenies. Am. Naturalist 154: 419-434.
Bennett, P.M. \& Owens, I.P.F. 2002. Evolutionary Ecology of Birds: Life Histories, Matings Systems and Extinction. Oxford University Press, Oxford.

Bretagnolle, V. 1993. Adaptive significance of seabird coloration: the case of Procellariforms. Am. Naturalist 142: 141-173.

Coyne, J.A. \& Price, T.D. 2000. Little evidence for sympatric speciation in island birds. Evolution 54: 2166-2177.

Cracraft, J. 1986. Origin and evolution of continental biotas: speciation and historical congruence within the Australian avifauna. Evolution 40: 977-996.

Cuthill, I.C., Bennett, A.T.D., Partridge, J.C. \& Maier, E.J. 1999. Plumage reflectance and the objective assessment of avian sexual dichromatism. Am. Naturalist 160: 183-200.

Darwin, C. 1871. The Descent of Man, and Selection in Relation to Sex. Murray, London.

Dobzhansky, T. 1940. Genetics and the Origin of Species. Columbia University Press, New York.

Endler, J.A. 1990. On the measurement and classification of colour in studies of animal colour patterns. Biol. J. Linnean Soc. 41: 315-352.

Endler, J.A. 1993. The colour of light in forests and its implications. Ecol. Monographs 63: 1-27.

Endler, J.A. \& Thery, M. 1996. Interacting effects of lek placement, display behavior, ambient light, and color patterns in three neotropical forest-dwelling birds. Am. Naturalist 148: 42 1-451.

Finger, E. \& Burkhardt, D. 1994. Biological aspects of bird coloration and avian colour vision including ultraviolet range. Vision Res. 34: 1509-1514.

Fisher, R.A. 1930. The Genetical Theory of Natural Selection. Clarendon press, Oxford.

Ford, J. 1987. Minor isolates and minor geographic barriers in avian speciation in continental Australia. Emu 87: 90-102.

Forshaw, J.M. 1989. Parrots of the World. Kevin Weldon and Associates, Australia.

Grant, P.R. 1965. Plumage and the evolution of birds on islands. Syst Zool. 14: 47-52.

Grant, P.R. 1975. The classical case of character displacement. In: Evolutionary Biology (T. Dobzhansky, M.K. Hecht, W.C. Steere, eds), pp. 283-309. Plenum Press, New York.

Grill, C.P. \& Rush, V.N. 2000. Analysing spectral data: comparison and application of two techniques. Biol. J. Linnean Soc. 69: 121-138.

Hamilton, W.D. \& Zuk, M. 1982. Heritable true fitness and bright birds: a role for parasites? Science 218: 384-387.

Hardy, J.W. \& Dickerman, R.W. 1965. Relationships between two forms of the red-winged blackbird in Mexico. Living Bird 4: 107-129.

Harvey, P.H. \& Pagel, M.D. 1991. The Comparative Method in Evolutionary Biology. Oxford University Press, Oxford.

Hausmann, F. 1997. The evolutionary significance of ultraviolet reflectance and florescence in birds. Honours Thesis. Department of Zoology and Entomology, University of Queensland, Australia.

Hausmann, F., Arnold, K.E., Marshall, J.N. \& Owens, I.P.F. 2002. UV signals in birds are special. Proc. R. Soc. Lond. B (in press).

Huxley, J.S. 1942. Evolution, the Modern Synthesis. Allen \& Unwin, London.

Immelmann, K. 1965. Australian Finches in Bush and Aviary. Angus and Robertson, Sydney.

Lack, D. 1968. Ecological Adaptations for Breeding in Birds. Chapman \& Hall, London. 
Lack, D. 1971. Ecological Isolation in Birds. William Clowes and Sons Ltd, London.

Lack, D. 1976. Island Biology, Illustrated by the Land Birds of Jamaica. Blackwells Press, Oxford.

Marchetti, K. 1993. Dark habitats and bright birds illustrate the role of the environment in species divergence. Nature 362: 149-152.

Mayr, E. 1942. Systematics and the Origin of Species. Columbia University Press, New York.

Mayr, E. 1963. Animal Species and Evolution. Harvard University Press, Cambridge.

Mayr, E. \& Stresemann, E. 1950. Polymorphism in the chat genus Oenanthe (Aves). Evolution 4: 291-300.

Moore, B.R. 1980. A modification of the Rayleigh test for vector data. Biometrika 67: 175-180.

Naguib, M. \& Todt, D. 1998. Recognition of neighbours' song in a species with large and complex song repertoires: the thrush nightingale. Journal of Avian Biol. 29: 155-160.

Orians, G.H. \& Christman, G.M. 1968. A comparative study of the behavior of red-winged, tricolored, and yellow-headed blackbirds. University of California Publications in Zoology. 84: 1-81.

Osorio, D., Miklósi, A. \& Gonda, Zs. 2001. Visual ecology and perception of coloration patterns by domestic chicks. Evol. Ecol. 13: $673-689$.

Owens, I.P.F. \& Bemett, P.M. 1994. Mortality costs of parental care and sexual dimorphism in birds. Proc. Roy. Soc. Lond. 257: 1-8.

Owens, I.P.F. \& Clegg, S.M. 1999. Species-specific sexual plumage: species-isolating mechanisms or sexually selected ornaments? In: Proceedings of the 22nd International Ornithological Congress, Durban (N.J. Adams \& R.H. Slowtow, eds), pp. 11411153. Birdlife of South Africa, Johannesburg.

Owens, I.P.F. \& Hartley, I.R. 1998. Sexual dimorphism in birds: why are there so many different forms of dimorphism? Proc. $R$. Soc. Lond. Ser. B 265: 397-407.

Park, S.R., Park, D.S., Kim, S.I. \& Yoon, M.B. 1995. Playback experiments on bush warblers (Cettia diphone): their song recognition of intra- and inter-population. Korean Journal of Zoology 38: 443-448.

Paterson, H.E.H. 1978. More evidence against speciation by reinforcement. S. Afr. J. Sci. 74: 369-371.

Paterson, H.E.H. 1985. The recognition concept of species. In: Species and Speciation (E.S. Vrba, ed.), pp. 21-29. Transvaal Museum Monograph no. 4. Transvaal Museum, Pretoria.

Paterson, H.E.H. 1993. Evolution and the Recognition Concept of Species. Johns Hopkins University Press, Baltimore.

Paterson, H.E.H. 1982. Perspective on speciation by reinforcement. S. Afr. J. Sci. 78: 53-57.

Pizzey, G. 1980. A Field Guide to the Birds of Australia. Angus and Robertson, Sydney.

Price, T. 1998. Sexual selection and natural selection in bird speciation. Philos. Trans. R. Soc. Lond., Ser. B 353: 251-260.

Saetre, G.-P., Moum, T., Bures, S., Kral, M., Adamjan, M. $\delta$ Moreno, J. 1997. A sexually selected character displacement in flycatchers reinforces premating isolation. Nature 387: 589-592. SAS Institute, 2001. JMP, Version 4.1. SAS Institute, Cary, NC.

Savalli, U.M. 1995. The evolution of bird plumage coloration and plumage elaboration: a review of hypotheses. In: Current Ornithology 12 (D.M. Power, eds), pp. Xx-Xx. Plenum Press, New York.

Schodde, R. \& Tidemann, S.C. (eds) 1997. 'Reader's Digest Complete Book of Australian Birds'. Reader's Digest Pty. Ltd., Sydney.
Serventy, V.N. (ed.) 1982. 'The Wrens and Warblers of Australia'. The National Photographic Index of Australian Wildlife. Angus and Robertson Publishers, Sydney.

Simpson, K. (ed.) 1984. 'Field Guide to the Birds of Australia. A Book of Identification'. Penguin Books Australia Ltd., Melbourne.

Strahan, R. (ed.) 1991. 'Honeyeaters and their Allies of Australia'. The National Photographic Index of Australian Wildlife. Angus and Robertson, Sydney.

Strahan, R. (ed.) 1992. 'Parrots and Pigeons of Australia'. The National Index of Australian Wildlife. Angus and Robertson, Sydney.

Strahan, R. (ed.) 1996. 'Finches, Bowerbirds and other Passerines of Australia'. The National Index of Australian Wildlife. Angus and Robertson, Sydney.

Sung, H.C. \& Park, S.R. 1994. Species recognition on the basis of song by yellow-throated bunting (Emberiza elegans). Korean Journal of Zoology 37: 573-579.

Vorobyev, M., Osorio, D., Bemett, A.T.D., Marshall, N.J. \& Cuthill, I.C. 1998. Tetrachromy, oil droplets and bird plumage colours. J. Comp. Physiol. A. 183: 621-633.

Wallace, A.R. 1889. Darwinism: An Exposition of the Theory of Natural Selection with Some of its Applications. Macmillan Publishers, London.

Zahavi, A. \& Zahavi, A. 1997. The Handicap Principle. Oxford University Press, New York.

Zar, J.H. 1974. Biostatistical Analysis, 2nd edn. Prentice Hall, Englewood Cliffs, NJ.

Received: 7 January 2002; revised 1 April 2002; Accepted: 15 April 2002

Appendix 1 Matched-pairs of species used in tests of the light environment hypothesis.

\begin{tabular}{llll}
\hline Relatively Open habitat & Display* & Relatively Closed habitat & Display* \\
\hline Lichenostomus chryops & $\mathrm{h}$ & Meliphaga lewenii & $\mathrm{h}$ \\
Lichenostomus virescens & $\mathrm{h}$ & Meliphaga notata & $\mathrm{h}$ \\
Lichenostomus flavescens & $\mathrm{h}$ & Lichenostomus hindwoodi & $\mathrm{h}$ \\
Lichenostomus keartlandi & $\mathrm{h}$ & Lichenostomus flavicollis & $\mathrm{h}$ \\
Meliphaga albilineata & $\mathrm{h}$ & Meliphaga gracilis & $\mathrm{h}$ \\
Lichenostomus fuscus & $\mathrm{h}$ & Lichenostomus frenatus & $\mathrm{h}$ \\
Lichenostomus cratitius & $\mathrm{h}$ & Lichenostomus leucontis & $\mathrm{h}$ \\
Manorina melanocephala & $\mathrm{w}$ & Manorina melanophrys & $\mathrm{W}$ \\
Erythrura gouldiae & $\mathrm{f}$ & Erythura trichroa & $\mathrm{h}$ \\
Neochmia phaeton & $\mathrm{h}, \mathrm{f}, \mathrm{b}$ & Emblema bella & $\mathrm{b}$ \\
Lonchura castaneothorax & $\mathrm{h}$ & Poephila cinta & $\mathrm{h}$ \\
Petroica goodenovii & $\mathrm{w}$ & Petroica rosea & $\mathrm{f}$ \\
Pachycephala rufiventris & $\mathrm{h}, \mathrm{t}$ & Pachycephala pectoralis & $\mathrm{h}, \mathrm{f}, \mathrm{t}$ \\
Cacatua roseicapilla & $\mathrm{h}$ & Cacatua galerita & $\mathrm{h}$ \\
Trichoglossus haematodus & $\mathrm{h}$ & Trichoglossus rubritorquis & $\mathrm{h}$ \\
Platycercus caledonicus & $\mathrm{f}, \mathrm{w}, \mathrm{t}$ & Platycercus adscitus & $\mathrm{W}, \mathrm{t}$ \\
Alisterus scapularis & $\mathrm{h}, \mathrm{w}$ & Polytelis swainsonii & $\mathrm{h}, \mathrm{w}$ \\
Glossopsitta concinna & $\mathrm{h}$ & Psitteuteles versicolor & $\mathrm{h}$ \\
Barnardius zonarius & $\mathrm{w}, \mathrm{t}$ & Eclectus roratus & $\mathrm{h}$ \\
Psephotus haematonotus & $\mathrm{w}, \mathrm{t}$ & Platycercus elegans & $\mathrm{w}, \mathrm{t}$ \\
\hline
\end{tabular}

*Display refers to those body regions used in active sexual display ( $\mathrm{h}=$ head, $\mathrm{f}=$ front, $\mathrm{b}=$ back, $\mathrm{w}=$ wing, $\mathrm{t}=$ tail $)$. 
Appendix 2 Trios used in tests of species isolation hypothesis.

\begin{tabular}{|c|c|c|c|}
\hline \multirow[b]{2}{*}{ Trichoglossus haematodus } & \multicolumn{2}{|c|}{ Allonatric nair of cnecies } & \multirow{2}{*}{$\frac{\mathrm{Max}^{*}}{\mathrm{~h}}$} \\
\hline & Trichoglossus chlorolepidotus & Trichoglossus rubritorquis & \\
\hline Glossopsitta concinna & Glossopsitta pusilla & Psitteuteles versicolor & $\mathrm{h}$ \\
\hline Platycercus elegans & Platycercus eximius & Platycercus caledonicus & $\mathrm{h}$ \\
\hline Meliphaga lewenii & Lichenostomus chryops & Meliphaga albilineata & $\mathrm{h}$ \\
\hline Meliphaga notata & Meliphaga gracilis & Lichenostomus versicolor & w \\
\hline Lichenostomus unicolor & Lichenostomus flavus & Lichenostomus leucontis & $\mathrm{h}$ \\
\hline Lichenostomus keartlandi & Lichenostomus flavescens & Lichenostomus hindwoodi & w \\
\hline Lichenostomus vs. versicolor & Lichenostomus flavus & Lichenostomu vs. fasciogularis & $h$ \\
\hline Lichenostomus f.fuscus & Lichenostomus melanop & Lichenostomus f. subgermana & $h$ \\
\hline Manorina melanocephala & Manorina flavigula & Manorina melanophrys & $\mathrm{h}$ \\
\hline Lichenostomus $p$. leilavalensis & Lichenostomus keartlandi & Lichenostomus p. pencillatus & w \\
\hline Lonchura castaneothorax & Erythura gouldiae & Erythura trichroa & $\mathrm{h}$ \\
\hline Poephila personata & Poephila cinta & Poephila acuticauda & $\mathrm{h}$ \\
\hline Neochmia temporalis & Emblema bella & Neochmia phaeton & $\mathrm{h}$ \\
\hline Malurus lamberti & Malurus cyaneus & Malurus melanocephala & $\mathrm{b}$ \\
\hline Petroica rosea & Petroica multicolor & Petroica goodenovii & $\mathrm{h}$ \\
\hline Pachycephala pectoralis & Pachycephala rufiventris & Pachycephala simplex & $\mathrm{h}$ \\
\hline Leptolophus hollandicus & Melopsittacus undulatus & Pezoporus wallicus & $\mathrm{h}$ \\
\hline Calyptorhynchus lathami & Calyptorhynchus funereus & Calyptorhynchus baudinii & $f$ \\
\hline Cacatua roseicapilla & Cacatua galerita & Cacatua sanguinea & w \\
\hline
\end{tabular}

*Max refers to those body regions of maximum contrast for the sympatric pairs ( $\mathrm{h}=$ head, $\mathrm{f}=$ front, $\mathrm{b}=\mathrm{back}, \mathrm{w}=$ wing, $\mathrm{t}=$ tail). 